\title{
O ESBOÇO HISTÓRICO-ETNOGRÁFICO- LINGÜÍSTICO DE UM POVO INDÍGENA
}

Maria do Socorro Pessoa*

RESUMO: O povo indígena Suruí Paíter reside hoje, em sua maioria, no Distrito do Riozinho, no Município de Cacoal, no Estado de Rondônia, Brasil. Esse povo sofreu todo o processo de invasão de suas terras por colonos imigrantes, especialmente quando da construção da BR 364, rodovia que liga o Estado de Mato Grosso a Porto Velho. O contato com os imigrantes provocou alterações profundas na vida desse povo nos mais diversos aspectos: cultura, religião e instalação da língua portuguesa no cotidiano de suas vidas. Este esboço histórico-etnográfico-lingüístico descreve alguns aspectos dessa "invasão" na vida dos Suruí Paíter do Riozinho, no Estado de Rondônia.

PALAVRAS-CHAVE: Suruí Paíter, Percurso Sociolingüístico, Lingüística.

ABSTRACT: Suruí Paíter indian people live today in Riozinho District, nearby Cacoal, in Rondônia in Brasil. This Indian people suffered all the process of invasion in their area by immigrant people, specially when BR-364 was built.This BR-364 conect Mato Grosso State to Porto Velho. The contact with immigrant people made several changes in Suruí Paíter life like: the culture, religion and the use of Portuguese language in their life. This historic-etnographic-linguistic text describe some aspects about the "invasion" in Suruí Paiter people from Riozinho District, in Rondônia state.

KEY WORDS: Suruí Paíter, Sociolinguistic Way, Linguistic.

*Prof ${ }^{a}$. Dr ${ }^{a}$ da Universidade Federal de Rondônia - UNIR Campus de 
Vilhena

\section{INTRODUÇÃO}

Os indígenas residentes em Rondônia, desde os primeiros contatos com os imigrantes vindos de todas as partes do Brasil para a região, assistiram a surpreendentes mudanças. Entre essas mudanças a mais marcante foi a construção da Rodovia Cuiabá-Porto Velho, hoje denominada BR-364. Com a conclusão da BR-364 abriu-se o caminho para a imigração de pessoas que buscavam o "Eldorado Rondoniense”, propagado em toda a mídia nacional pelo Governo Brasileiro. Em conseqüência, a população de Rondônia passou de 85.504 pessoas em 1960, para 111.064 em 1970 e 490.153 em 1980 (IBGE, Censo Demográfico, 1960 a 1981). O maior crescimento ocorreu, porém, na década de 1970, o que fez com que as cidades ao longo da BR-364 crescessem assustadoramente, dando à região motivos mais que suficientes para conflitos e lutas. Percebe-se, assim, que era inevitável que, com tal crescimento, a luta pela terra ocorresse desenfreadamente, iniciando-se, infelizmente, a ocupação das áreas indígenas, cujas terras foram sendo comprimidas e ameaçadas, num cerco cada vez mais fechado de violência, lutas e conflitos. Como se não bastasse toda a usurpação territorial e a conseqüente eliminação física de milhares de indígenas, os nãoíndios desenvolveram e utilizaram armas mais sutis de dominação e massacre, nos mais diversos domínios dos povos indígenas, inclusive no âmbito da cultura. Não foi diferente com o povo Suruí Paíter, nosso objeto de pesquisa.

Os Suruí, residentes no Distrito do Riozinho, têm como língua materna a Língua Suruí, do grupo de línguas Tupi-Mondé, usada na vida tradicional da comunidade. A bibliografia sobre esta nação indígena é praticamente inexistente, mas DAL POZ (1991, p. 25) nos fornece dados relevantes quando explicita:

... a bibliografia sobre os Suruí é ainda escassa. Os missionários W. C. Bontkes, do Summer Institute of Linguistic, durante vários anos estudaram sua língua (Bontkes 1978, apud Moore 1984,p. 8), e obtiveram 
alguns dados sobre organização social e parentesco (BONTKES 1974). Os missionários Lori Altmann e Roberto Zwetsch (1980), da IECLB, traçaram um histórico dos contatos e um relato sumário de suas observações ao longo de um ano de permanência entre eles. Betty Mindlin, que os pesquisou entre 1979 e 1983, apresentou uma descrição despretenciosa do modo de vida Suruí, na qual destacou o sistema de nominação e a instituição do ritual de metades, que divide o grupo entre "mato" e "aldeia" a cada estação seca (MINDLIN, 1985). Quanto à mitologia, incluiu alguns fragmentos míticos. Dados escatológicos esta autora havia publicado anteriormente (MINDLIN, 1982). Os Suruí foram ainda estudados por Carlos Coimbra (1985), interessado em ecologia humana, e por Leda Leonel (1984), quanto à arquitetura e meio-ambiente.

Segundo o CIMI (Conselho Indigenista Missionário), em documento de 1998, o primeiro contato do povo Suruí Paíter com a sociedade envolvente deu-se em junho de 1969, através da FUNAI, no acampamento Sete de Setembro, fundado no dia 07 de Setembro de 1968 (daí a origem do nome de uma das aldeias do povo Suruí Paíter). O contato foi feito pelo sertanista Apoema Meirelles e seu pai, ambos pertencentes à FUNAI. O lugar onde ocorreu o primeiro contato é chamado, pelos Suruí Paíter de "Nambekó-dabadaki-ba", que significa "o lugar onde os facões foram pendurados", numa referência aos presentes que Apoema Meirelles e seu pai ali deixaram para os indígenas: machados, facões, panelas, facas e canivetes. Em 1969 os Suruí Paíter eram, aproximadamente, 4.000 índios. De 1970 a 1974, sua população reduziu-se a aproximadamente 600 pessoas: muitos morreram por causa de sarampo, gripe e tuberculose. Suas terras foram constantemente invadidas e essa questão só foi resolvida definitivamente em 1981, com a retirada dos posseiros da área Sete de Setembro (FUNAI, 2002). Atualmente, os Suruí Paíter formam um grupo de cerca de 740 pessoas que habita nas fronteiras dos Estados de Rondônia e Mato Grosso, no parque Aripuanã, 
com extensão de 220.000 hectares e onde estão instalados dois postos da FUNAI: o PIN Sete de Setembro e o PIN Linha 14. A área original do parque Aripuanã era, na verdade, um território contínuo que englobava os vários grupos Tupi-Mondé que formam um grande complexo cultural (DAL POZ, 1991). Suas terras, por estarem muito próximas da BR-364, estão cercadas por colonos, e, por isso, os Suruí Paíter sempre foram muito vulneráveis aos efeitos da colonização. $\mathrm{Na}$ época do contato, a população Suruí Paíter foi calculada em 600 pessoas, por Jean Chiappino (1971). Nos anos 70 , houve muitas mortes causadas por doenças trazidas pelo homem branco, reduzindo-se a população a 272 pessoas. Dos anos 80 até os nossos dias, passou a haver um grande crescimento populacional, e hoje os Suruí Paíter somam cerca de 750 pessoas entre homens, mulheres, crianças, jovens e adultos. Nos anos 80 , devido às invasões de suas aldeias por colonos, o povo Suruí se dividiu por grupos familiares, ficando confinado em estradas da área indígena nas Linhas 8, 9, 10,11, 12 e 14. Na década de 1990, iniciaram o processo de migração para o Distrito do Riozinho à busca de melhorias de vida para seus grupos, especialmente junto ao Posto da FUNAI, com sede ali estabelecida.

\subsection{A ALDEIA E O PERÍODO DO PRÉ-CONTATO}

$\mathrm{Na}$ aldeia o centro da vida era a casa grande, a casa mais importante do Nambekô-dabada-quibá-coco, como é chamado pelos Paíter o conjunto de malocas. Na casa grande, a família vivia e se relacionava como família nuclear - pai, mãe e filhos. Só nos momentos mais importantes, quando faziam uma grande caça, todos se juntavam num ritual de partilha. Os homens caçavam e providenciavam a carne e as mulheres podiam acompanhá-los nessas tarefas. As outras fontes de alimentação vinham da floresta, como a castanha, o mel, os frutos. A tarefa de pescar era de todos: homens, mulheres e crianças. Quando necessitavam prevenir a fartura e a produção, invocavam os espíritos - Hô-êi -ê-tê - pois, para os Suruí Paíter, a invocação dos espíritos era sempre 
necessária. Antes do contato com a sociedade envolvente, o povo Suruí Paíter utilizava-se apenas da sua língua, o Suruí, em todo tipo de comunicação com seus pares.

\subsection{DO CONTATO À ATUALIDADE}

Com a criação em 1907 da Comissão de Linhas Telegráficas e Estratégicas de Mato Grosso ao Amazonas (a conhecida Comissão Rondon), por ato do presidente da República Afonso Pena, planejase a ocupação sistemática e permanente do noroeste do então imenso Estado de Mato Grosso: além de estender o telégrafo, abrir estradas estratégicas, executar trabalhos geográficos, botânicos e mineralógicos, a Comissão Rondon encarregou-se de "pacificar" as populações indígenas em seu percurso. Os primeiros contatos, nem sempre pacíficos, entre os índios que aí viviam e elementos da sociedade nacional, deram-se em torno das estações telegráficas de Vilhena, José Bonifácio, Barão de Melgaço e Pimenta Bueno, inauguradas pela Comissão Rondon entre os anos de 1912 e 1915 (CIMI, 1998), quando toda a linha de Cuiabá a Santo Antônio do Madeira entrou em funcionamento. Relatos circunstanciados, traçando os diversos surtos pelos quais se deu a colonização de Rondônia e adjacências, e caracterizando os danos causados à população indígena, podem ser encontrados em Meirelles (1984) e Brunelli (1985). Certo é que, apesar de tudo, subsistiu nessa região um número considerável de grupos indígenas, entre eles os Suruí Paíter. No início do contato, os Suruí Paíter foram, em várias situações, confundidos com os Cinta-Larga. DAL POZ (1991, pp.92, 93).

A partir do primeiro contato do povo Suruí Paiter com os nãoíndios, o intérprete da FUNAI foi de fundamental importância para suas vidas. Era esse intérprete que proporcionava a compreensão da linguagem que os Suruí Paíter careciam ter para suprir as necessidades de comunicação com a sociedade envolvente ou para a comunicação com a própria FUNAI. Com o passar do tempo, já não bastava a comunicação feita pelo intérprete. O povo Suruí Paíter sentia necessidade de aprender a língua daquele intérprete 
para compreender o novo mundo que se estabelecia em suas terras e à sua volta. Nesse sentido, podemos afirmar que, a partir das relações com os intérpretes da FUNAI, a língua portuguesa foi adentrando à comunidade da nação indígena Suruí Paíter. $\mathrm{O}$ contato com o homem branco fez com que o povo Suruí Paíter passasse a ter alterados, não só os seus costumes tradicionais, mas também a própria maneira de convivência com seus pares. Ter os costumes tradicionais alterados parece constituir-se um processo "normal" para os olhos da sociedade em nosso país, especialmente quando tais alterações referem-se aos grupos de minorias, muito mais expostos a processos de "devastação" e, ainda, especialmente, se tais minorias são indígenas. Sabemos que o "contato" do indígena com o homem branco sempre foi, historicamente, prejudicial ao primeiro. Heckenberger (2001, p.77) nos confirma como isso ocorreu na região Amazônica:

$\mathrm{Na}$ Amazônia, vários povos nativos, muitos dos quais radicalmente diferentes dos que conhecemos hoje, foram dizimados nas primeiras situações de contato (PORRO, 1996; ROOSEVELT. 1991; WHITEHEAD, 1994). Fatores como escravidão, ações punitivas, deslocamentos forçados, além de etnocídio explícito, provocaram a dissolução ou fuga de muitos povos amazônicos logo após os primeiros contatos (KIEMAN, 1954). Entretanto, como em outros lugares da América, os efeitos provocados pela vanguarda da expansão européia - personificada pelos quatro cavaleiros do apocalipse: Praga, Fome, Guerra e Morte - ultrapassaram largamente o contato propriamente dito com os europeus. Mais do que a interação direta, foram as forças indiretas, invisíveis, do "contato" europeu que moldaram a história do contato para a maior parte dos povos amazônicos.

Se não há novidades quanto ao fato de modificações drásticas na vida indígena dos Suruí Paíter, quando comparados com outras nações indígenas que passaram pelo mesmo processo de 
envolvimento com a nova sociedade, há, nesta comunidade, um motivo que se tornou relevante para a Lingüística e, em especial, para o trabalho sociolingüístico: os Suruí Paíter "praticam”, publicamente, um discurso de super-valorização de sua língua, de sua cultura e de sua condição de "ser índios", mas, na verdade, já há algum tempo exibem um conjunto de comportamentos e práticas, entre eles o uso da língua portuguesa, muito próximos da vida e das ações do homem branco, como detalhado em PESSOA, (2003, p. 54).

Na década de 80 , do século XX, os Suruí Paíter iniciaram suas intermináveis viagens da aldeia para o asfalto e do asfalto para as aldeias. Partindo das Linhas 8, 9, 10, 11, 12 e 14, eles passaram a se encontrar no Distrito do Riozinho, permanecendo no Posto da FUNAI por longos períodos de espera, aguardando médicos, remédios, roupas, alimentos. No início iam nus, enfeitados com seus ornamentos significativos para demonstrar situações particulares. Desconsiderando essas ornamentações tradicionais, os agentes da FUNAI foram providenciando roupas para que se vestissem, tomassem banhos de chuveiro, usassem medicamentos da medicina ocidental. Buscar recursos junto ao posto da FUNAI, no Distrito do Riozinho, para continuarem saudáveis, foi o grande motivo, ou senão o motivo inicial da peregrinação que os Paíter iniciaram das aldeias para o Posto da FUNAI. Doenças como a gripe, o sarampo e a tuberculose foram tão letais para os Suruí Paíter que dizimaram muito mais da metade de sua população se observarmos a população existente antes do contato com o homem branco. Todos estão de acordo sobre as mudanças introduzidas com o contato e sobre o fato de que antigamente existiam menos doenças. O período dos primeiros contatos e as epidemias que lhe seguiram é uma lembrança muito viva na memória dos Suruí Paíter, que crêem que, mesmo se, atualmente, estas doenças não têm mais os mesmos efeitos catastróficos de antes, sua saúde foi irremediavelmente afetada pelo contato. Vemos, assim, que os Suruí Paíter têm plena consciência de que as modificações introduzidas pelo contato estão na origem de seus problemas de 
saúde e de pobreza. Mas os costumes dos brancos já invadiram irremediavelmente suas vidas e também suas atuais aldeias. Antes de ir ao "médico", eles tentaram de tudo, pois em sua cultura vários espíritos comandam os males e as doenças, como por exemplo, aquelas causadas pelas almas dos mortos atormentando o sono dos que os mataram. Mas depois de muito lutar e não conseguir vencer o sarampo e a tuberculose, eles terminaram por aceitar a "enorme ajuda" da FUNAI e passaram a receber medicamentos e consultas no Distrito do Riozinho, a zona urbana cortada pela BR-364, de asfalto novo, que traz imigrantes, novos colonizadores. A aldeia era o espaço natural, onde ficavam muitas mulheres e crianças, aguardando os homens que, sempre juntos, vinham à FUNAI para levar saúde para casa. Com dificuldade em expressar-se em língua portuguesa, sentiram-se forçados a aprender essa nova língua, da qual nada compreendiam ou compreendiam apenas o que haviam aprendido nos primeiros anos de contato. Nem sempre o "intérprete" da FUNAI estava ali para "ajudá-los" em suas reivindicações.

As alterações na vida Suruí Paíter ocorreram com grande velocidade e, rapidamente, o doente em uma família da aldeia já não vinha sozinho ao Posto da FUNAI Quando um índio ficava doente, os demais membros da família acompanhavam-no até o Distrito e lá ficavam até a recuperação de seu parente enfermo. Nas longas esperas por atendimentos diversos aprenderam a comer a comida do branco, aprenderam a comunicar-se em língua portuguesa, aprenderam a entregar madeiras nobres em troca de comida, de roupas, de saúde, de bem estar. Aprenderam, também, a ver as imagens na televisão instalada no Posto da FUNAI, e conheceram outros mundos, viram outras lutas, outros retratos da violência. Já não ficavam sob o luar conversando e brincando. Ficavam sob a luz elétrica, presos à televisão, dormindo em camas, e quando estas faltavam, dormindo ao relento, nas varandas do "ponto de apoio", como também é conhecido o Posto da FUNAI. Aprenderam, a duras penas, que era preciso viver bem com esse homem branco, "o Yara", como denominam a comunidade não 
índia, porque esse homem é poderoso, possui armas, carros, televisão, dinheiro. O constante deslocamento do povo Suruí Paíter no vai-e-vem da aldeia para o asfalto e do asfalto para a aldeia é sempre causado pelo conflito: estar no Distrito com saudades da vida livre da aldeia; estar na aldeia sem o conforto da televisão, das comidas compradas nos "boliches" (nome dado às pequenas mercearias do Distrito do Riozinho) e da falta de medicamentos para os filhos. Este vai-e-vem provoca a inserção de elementos não indígenas nas aldeias. É muito comum encontrar, hoje, nas malocas, potinhos de iogurtes, comidas enlatadas (sardinha, margarina, etc.), ao mesmo tempo em que se encontram, nas geladeiras das casas indígenas do Distrito, a carne de macaco, a mandioca, o cará, para as refeições.

O crescente contato dos Suruí Paíter com a sociedade envolvente tem provocado conseqüências nas relações sociais da comunidade. A disputa por terras, os conflitos entre famílias, a necessidade de consumismo desenfreado e a grande vontade de ter dinheiro coloca esta nação indígena em meio a toda a violência da região, tais como: assassinatos, crimes jamais desvendados e índios que desaparecem de sua comunidade. Muitos Suruí Paíter são assassinados e há casos de estupro nunca desvendados, pois as meninas e moças ficam expostas ao longo da BR-364, residindo muito próximas ao movimento que a rodovia traz. À medida em que têm suas terras invadidas, suas madeiras vendidas ilegalmente, os bens da floresta explorados e consumidos, nada lhes resta a não ser perambular pelas ruas do Distrito do Riozinho, ou ir para Espigão D'Oeste, ou Cacoal, cidades que nunca os acolhe bem e onde são, inclusive, presos. São presenças constantes nos noticiários policiais, tanto da imprensa falada quanto da imprensa escrita, como mostramos a seguir:

ÍNDIOS QUEREM LIBERDADE - Índios da etnia Surui, liderados por 4 caciques continuam aguardando na Fundação Nacional do Indio (FUNAI), em Cacoal, a liberdade dos índios José Naraicola e Júnior Suruí, autuados em flagrante, pela Polícia Federal, no 
último final de semana, acusados de exploração ilegal de madeira na Aldeia 7 de Setembro. O advogado Antonio Júlio Ribeiro informou que a decisão judicial, autorizando ou não a liberação dos dois indígenas, deve sair ainda hoje. Os índios Suruí querem saber quais são as propostas do governo para contrapor as atividades consideradas ilícitas, das quais hoje são dependentes para adquirir os bens industrializados, necessidades impostas pelo contato com a sociedade branca. Os Suruí querem discutir também com o presidente da FUNAI os limites de suas terras (Aldeia 7 de Setembro), uma vez que o espaço pertencente à reserva não estaria bem sinalizado, o que estaria permitindo a invasão de suas terras. Querem, também agilidade no processo de demarcação da área Tucum, o que, segundo os caciques, já é de conhecimento da Fundação Nacional do Índio, em Brasília. A prisão dos dois indígenas foi levada ao conhecimento do presidente da FUNAI, Glênio Costa Alvarez, pela organização Metarelá do Povo Indígena Suruí, na quarta-feira. Eles continuam presos em Pimenta Bueno, sob a custódia da polícia civil. No documento enviado a Brasília, os caciques cobram a presença de Glênio Costa, acompanhado da Procuradoria da FUNAI, do Ministério Público Federal e da Polícia Federal, em Cacoal, para discutir a prisão de índios nas terras por eles habitada, além de outros problemas que estariam afetando as comunidades indígenas. $\mathrm{O}$ advogado dos Suruí, Antonio Júlio Ribeiro, disse não concordar com a prisão dos dois índios. Ele entende que a polícia precisa de mandado judicial para entrar em terra indígena. Sobre a exploração dos recursos naturais, por parte das comunidades indígenas, o advogado cita o artigo 231, da Constituição Federal, parágrafo $2^{\circ}$. "As terras tradicionalmente ocupadas pelos índios destinamse a sua posse permanente, cabendo-lhes o usufruto exclusivo das riquezas do solo, dos rios e dos lagos nelas existentes." Júlio Ribeiro defende a implantação de um plano de manejo florestal na região e discorda 
da maneira como os índios vêm sendo tratados pelos órgãos repressores."

(http:/www.diariodaamazonia.com.br/didad.php3 $-29 / 07 / 2002)$

\subsection{O VAI-E-VEM DOS SURUÍ PAÍTER: UM PERCURSO MARCADO POR SAUDADES, CRIMES, CHACINAS, VENDAS DE MADEIRA, SAÚDE E EDUCAÇÃO PRECÁRIAS, CRISES LINGÜÍSTICAS E SOCIAIS}

Definitivamente, após o contato, os Suruí Paíter se deslocam da aldeia para o asfalto e vice-versa, numa espécie de vai-e-vem constante. Esse vai-e-vem não tem afetado apenas suas festas, suas reuniões, seus rituais, suas construções e suas comidas. Suas práticas de linguagem sobre os fatos de suas vidas alteram-se constantemente, num crescente conflito de desejar preservar sua história e de integrar-se às necessidades do cotidiano em contato com a sociedade envolvente. Outro exemplo ilustrativo diz respeito à religião. Tradicionalmente, o Hoeietê era a festa sagrada para invocar saúde e fartura de colheita, ou como ritual de cura, quando havia alguém doente. O Hoeietê acontece raramente hoje em dia e nem todos os Suruí residentes no Distrito se deslocam para a aldeia por ocasião desse ritual sagrado, seja porque são proibidos de freqüentá-lo, por freqüentarem outras religiões do Distrito do Riozinho (em geral evangélicas), seja porque já não se interessam por essa tradição.

O vai-e-vem da aldeia para o asfalto e do asfalto para a aldeia está delineando a perda das raízes culturais do povo Suruí Paíter, cujos grandes representantes são os jovens e as crianças. No conflito do vai-e-vem e apesar de toda essa intervenção, os Suruí dizem que seu espírito está voltado para valorizar e conservar, sempre, o passado e as experiências vividas pelos ancestrais, na perspectiva de efetuar uma melhor formação dos jovens na vida futura. Nosso trabalho de campo, porém, não confirmou esse discurso corrente. É preciso ressaltar que, ao negar as visíveis mudanças em seu grupo, os Suruí Paíter estão tentando manter-se como nação indígena por diversas 
razões: não perder o status de "povo indígena" tão valorizado na região Amazônica e aos olhos do mundo em geral, não perder os parcos "benefícios" que a FUNAI ainda lhes proporciona depois de ter permitido as invasões de suas reservas; tentar recuperar as terras que lhes pertencem e que lhes foram roubadas. Nesse sentido, a situação lingüística do povo Suruí Paíter é tão peculiar quanto a sua situação de contato, que envolve múltiplos agentes atuando de diferentes formas. O conflito social provocado pelo constante vai-e-vem dos Suruí Paíter gerou, então, práticas de linguagem também conflituosas, de discursos incoerentes ou não condizentes com a realidade lingüística que observamos no Distrito do Riozinho. Esse conflito lingüístico aprofunda-se no cenário dos intensos contatos com os madeireiros, com os policiais que são chamados para amenizar conflitos do comércio ilegal de madeira, as autoridades em geral e, não poucas vezes, entre os Suruí Paíter da zona urbana versus os residentes nas aldeias. Podemos apontar que a mola propulsora do conflito social para os Suruí Paíter tem sido o comércio da exploração de madeira, que teve início em meados da década de 80 , do século XX, e tem sido atualmente a principal fonte de renda desse povo indígena, sendo que, na maioria dos casos, a distribuição desta renda não é eqüitativa, "beneficiando" basicamente um número reduzido de pessoas. Em princípio, a retirada de madeira era seletiva e direcionada para as espécies de maior valor do mercado, como mogno e cerejeira. Atualmente, nas áreas onde este potencial de madeiras nobres se encontra esgotado, a retirada se estende a outras espécies, de menor valor comercial, as chamadas "madeiras brancas", como garapeira, angelim pedra, ipê, cedro rosa e madeiras para laminação Os Suruí Paíter têm consciência dos malefícios decorrentes deste tipo de exploração, mas continuam possibilitando que em todos os anos ela se repita. Os órgãos governamentais responsáveis pela proteção e fiscalização também não tomam providências cabíveis, na época adequada, e este tipo de exploração altamente predatória, em áreas de preservação permanente, com imensos prejuízos para os índios, se apresenta como permissível, pois qualquer cidadão comum tem 
conhecimento destes fatos. Nesse sentido, o vai-e-vem dos Suruí Paíter está sempre marcado pela presença desses "vendedores" de madeiras, dos "compradores" de bens naturais da floresta, de discussões intermináveis e de negociações sempre desfavoráveis aos Paíter. Costumes, tradições e linguagem estão se perdendo pelos percursos da aldeia ao asfalto e do asfalto para a aldeia. Muitas vezes, atualmente como no passado, esse percurso é marcado por crimes e assassinatos. Doentes e empobrecidos, explorados economicamente e correndo riscos de perder a totalidade de suas terras, os Suruí Paíter exigem, cada vez mais, escolas e saúde para seus filhos. Pelos relatos apresentados, após o contato dos Suruí Paíter com o homem branco inúmeras alterações ocorreram na vida desse povo indígena e, o que se vê hoje é um incessante percurso: aldeia/cidade/aldeia com o uso da língua portuguesa. Além disso, o contato com o homem branco criou, para o grupo Paíter, necessidades antes desconhecidas, como por exemplo: necessidade de escolas com o conseqüente uso da língua portuguesa; dependência em relação à saúde - o ritual tradicional de invocação à saúde foi substituído pela procura de remédios usados pelos homens brancos; os cultos tradicionais do Pajé estão sendo substituídos pelas religiões ocidentais; casavam apenas entre si, mas no Distrito do Riozinho estão se envolvendo com relacionamentos externos ao grupo (o namoro); estão havendo mudanças nas relações físicas, sociais e culturais. Na realidade, no vai-e-vem e no grande conflito social já estabelecido por esse percurso, os Suruí Paíter tentam aproximar-se sempre mais do homem branco. Nossas observações nesse sentido são confirmadas pelo trabalho de Santilli (1987), uma coletânea de depoimentos, experiências pessoais e fotografias que retratam, especialmente, o povo Suruí Paíter residente no Distrito do Riozinho. Santilli usa a expressão “ÀRE” para enfatizar como os Suruís, em seu idioma, chamam os demais povos indígenas que convivem no Estado de Rondônia. Ao mesmo tempo, explica que os Suruí já denominam, na época, também os homens "civilizados" com a expressão “ÀRE”, possivelmente, segundo o autor, numa tentativa de aproximação no mais novo Estado brasileiro, que ele 
denomina "a Terra de Rondon". ÀRE é também parte do "Projeto Nharamaã" de documentação áudio-fotográfica da colonização de Rondônia, cujo objetivo é o registro das transformações sócioambientais da região. Em resumo, os resultados que obtivemos a partir deste estudo é que a perda da língua étnica entre os Suruí Paíter do Distrito do Riozinho está ocorrendo mais amplamente do que podíamos esperar e que a maioria deles tem o português como a língua de prestígio para a comunidade. Apesar da insistência dos idosos na preservação da língua Suruí, com o falecimento desses é provável que essa desapareça, sobretudo porque os atuais adultos, futuros idosos, estão mergulhados no mundo da língua portuguesa. Não gostaríamos de apontar isso, mas, é muito provável que esse desaparecimento seja tão rápido quanto tem sido o desaparecimento das madeiras nobres, das aves, dos animais e das riquezas naturais das aldeias dos Suruí Paíter!

\section{REFERÊNCIAS}

BECQUELIN; GUIRARDELLO. Histórias Trumai. In: FRANCHETTO B.; HECKENBERGER. Os povos do Alto Xingu. Rio de Janeiro, Ed. UFRJ, p. 437, 2001.

BISINOTO, L. S. J. Atitudes Sociolingüísticas em Cáceres-MT: efeitos do processo migratório. Dissertação de Mestrado. IEL/ UNICAMP-SP, p. 47-60, 2000.

BLACK, F. Infectious disease in primitive societies. In: Science. pp. 187; 515-518, 1975.

BONTKES, W.; BONKLES, C. Os Suruí (Tupian) Social Organization. Summer Institute of Linguistics. Ms, 1974.

CIMI-Conselho Indígena Missionário. Panewa Especial. Revista Missionária. Porto Velho, 1996, 1997, 1998, 2000, 2001.

DAL POZ, J. No País dos Cinta-Larga: uma etnografia do ritual. 
Dissertação de Mestrado. SP. Faculdade de Filosofia, Letras e Ciências Humanas, USP. p.19-21-24- 25-38-39-40-41-92-93, 1991.

FRANCHETTO, B; HECKENBERGER, M. (Org). Os povos do Alto Xingu - História e Cultura. Rio de Janeiro: Editora da UFRJ, p. 77-156, 2001.

FUNAI - Fundação nacional do Índio. Relatórios de 1960 a 2001. 
